\title{
PRESSURE SORE PREVENTION FOR THE WHEELCHAIR- BOUND SPINAL INJURY PATIENT
}

\author{
By M. W. Ferguson-Pell, B.Sc., Ph.D.; I. C. Wilkie, B.Sc., Ph.D.; \\ J. B. Reswick, Sc.D.; and J. C. BARBENEL, B.D.S., M.Sc., L.D.S.(Eng.) \\ Bioengineering Unit, University of Strathclyde, Glasgow, Scotland, and \\ Rancho Los Amigos Hospital, U.S.A.
}

\begin{abstract}
The concept of a wheelchair cushion fitting clinic for the prevention of pressure sores is reviewed in the light of recent estimates of the cost of pressure sores in the U.K. A method for measuring the pressure beneath the ischial tuberosities is discussed and techniques for measuring a patient's habitual exercise frequency and seated posture are described. Results from the records of 600 spinal injury patients attending Rancho Los Amigos Hospital are reported and used to demonstrate the importance of low pressure beneath the ischial tuberosities as an indicator of wheelchair cushion suitability.
\end{abstract}

Key words: Pressure measurements; Pressure sores; Wheelchair cushion.

\section{Introduction}

PRESSURE sores are skin lesions most frequently developed by patients with diminished or absent cutaneous sensation or who are severely restricted in their ability to move. Conservative estimates of the cost of pressure sores in the U.K. based on a weekly cost per patient of $£ 200$ per week exceeds $£ 60$ m per annum (Barbenel et al., I977).

In addition to the economic costs of pressure sores, vitally important social and humanitarian costs are involved for the patient and his family. Apart from the distressing appearance of pressure sores and their debilitating effects, repeated, prolonged hospitalisation due to pressure sores is disruptive to the family unit and an additional disability for the patient.

In an effort to reduce the incidence of pressure sores, numerous mattresses, special beds, wheelchair cushions and other support systems and treatments have been developed which claim to provide a significant improvement upon conventional supports and/or techniques. The result has been a substantial increase in pressure sore awareness coupled with widespread confusion concerning the relative merits of the many 'devices' available. Therapists and nurses responsible for the prescription of support systems for patients in their care clearly require some guidance on the relative merits of the many devices available in order to ensure their suitability for the patient according to the category of his disability and his individual requirements.

Most commercial wheelchair cushions are supplied to suit an assumed variety of needs for a general patient population. In many cases the wheelchair cushions are used by patients with full sensation who require a cushion to improve the comfort of their wheelchair. There is, however, the very important group of patients who rely upon a wheelchair cushion to reduce the mechanical stresses which locally occlude the supply of blood to the skin and in time may be responsible for the development of pressure sores. In recent years the latter group has been clearly differentiated by some wheelchair cushion manufacturers and a number of 
cushions have been developed specifically for pressure sore prevention. Although many patients find these cushions effective, ischial pressure sores developed during wheelchair use still remain a serious problem.

In recognition of the multifactorial aetiology of pressure sores a number of therapy and research programmes have responded by developing the process of patient/support matching to provide a 'tailor-made' fit of the wheelchair cushion to the patient (Rogers, I973; Cox, 1974; Nelham, 1975; Reswick \& Rogers, 1976; Ferguson-Pell, 1977; Manley et al., 1977; Ferguson-Pell \& Wilkie, 1978). A good example of this approach which employs quantitative measures to assess the quality of the patient/support match is the Pressure Clinic, a name coined by Rogers (I973) to describe a spinal injury out-patients' clinic at Rancho Los Amigos Hospital (Downey, U.S.A.) which specialises in fitting wheelchair cushions fashioned from blocks of flexible foamed polyurethane.

Following collaboration with the Rancho Los Amigos Rehabilitation Engineering Group the authors have developed and refined the pressure clinic concept at Philipshill Hospital Spinal Injuries Unit (Busby, Glasgow). Data have been collected both from the Rancho and Philipshill pressure clinics, the statistical analyses of which appear to endorse the pressure clinic approach to pressure sore prevention for the spinal injury wheelchair user.

\section{The Pressure Clinic}

The pressure clinic concept was developed by Rogers (1973) to permit several basic principles of pressure sore prevention to be put into effect in the clinical environment. Effective pressure sore prevention requires that the body weight be distributed such that areas over bony prominences (such as the ischial tuberosities) sustain only small pressures which the patient should completely and regularly relieve when performing press-ups. In order to measure the pressure distribution beneath each patient, a simple pressure transducer was developed by Rogers (I973) which is now available commercially (Talley, U.K.).

The techniques of wheelchair cushion construction employed by the Rancho group and described in detail by Rogers (1973) have been refined by the present authors. The majority of the cushions supplied incorporate a high density polyurethane foam block cut to the size of the wheelchair base and excavated in the region corresponding to the location of the ischial tuberosities (Fig. I). Some patients are found to have acceptably low pressures beneath their ischial tuberosities using a plain unexcavated foam block while others are found to have unacceptably high sub-ischial pressures even after excavation. In the latter case the provision of a bar of foam placed anteriorly to the excavated region was found by Rogers (I973) to preferentially load the upper thighs while removing most of the load from the ischial tuberosities. In all cases it is recognised that the most acceptable support is that which provides the required relief with the least modification of the foam block.

The range of sub-ischial pressures that Rogers considered acceptable was determined initially by experience and observation of the presence of adverse skin reactions such as reactive hyperaemia or prolonged erythema. Rogers considered that the maximum sub-ischial pressure should be approximately $30 \mathrm{mmHg}$ $(4.0 \mathrm{kPa})$. The authors have found this difficult to achieve with some patients with abnormal sitting postures and will accept as 'safe' sub-ischial pressures as high as $60 \mathrm{mmHg}(8 \cdot 0 \mathrm{kPa})$, provided that the patient presses up more frequently.

Detailed records of the measurements taken and the modifications made to 


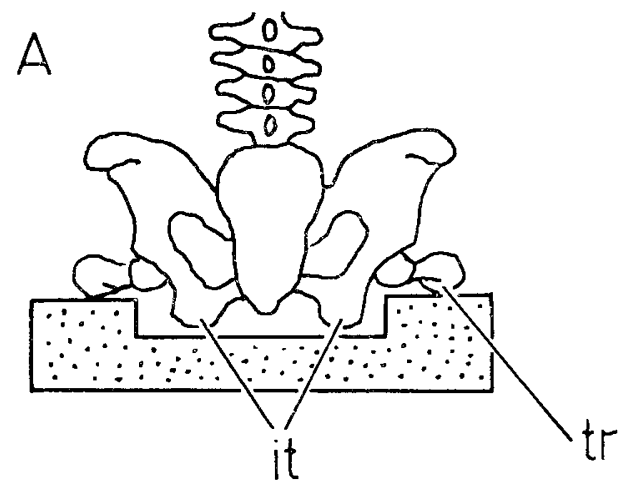

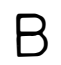

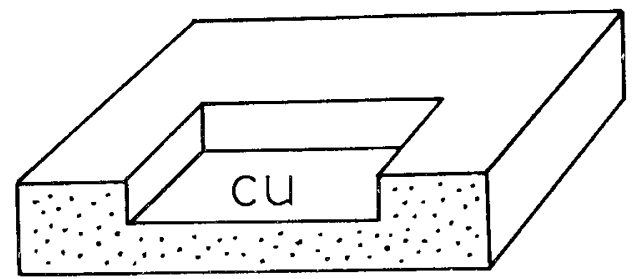

FIG. I

Diagrammatic rear view (A) (with subject in situ) and oblique view (B) of a wheelchair cushion with ischial cut-out (cu). Body weight is transferred from the ischial tuberosities (it) to the greater trochanters (tr).

the patient's support are kept by staff at both the Rancho and Philipshill pressure clinics. Apart from providing feedback for research purposes, these records enable changes in the patient's requirements to be monitored which, if necessary, may be rectified by appropriate methods.

In all cases it is necessary for the patient to return to the pressure clinic regularly. Even the most durable foam cushions are likely to require replacement within 12 months of fitting. Cushion wear is usually accompanied by substantial increases in sub-ischial pressure. The authors have recorded pressure increases in excess of 80 per cent over 6-month periods of use, which must inevitably increase the risk of tissue damage. The authors consider that once a patient has been referred to the pressure clinic for wheelchair cushion fitting the responsibility for his care is a long-term commitment.

\section{Further Developments of the Pressure Clinic Concept}

The authors are currently investigating methods of further refining the techniques used in the pressure clinic in order to reduce the persistent core of patients who, despite the processes of patient/support matching described above, continue to develop pressure sores. In some cases these sores may not be attributable to wheelchair cushion use but to an inadequate car seat or armchair. There is a clear need to use pressure clinic techniques for these supports, a need that is being met at the Rancho and Philipshill pressure clinics.

\section{Assessment of Exercise Frequency}

When fitting wheelchair cushions to individual patients it is necessary to consider their ability (or willingness) to exercise and provide pressure relief in the skin covering the ischial tuberosities. The relationship between pressure, the duration for which it is applied, and resulting tissue damage, as demonstrated by Kosiak (1959) and Reswick and Rogers (1976), suggests that a patient with lower exercise frequency than average may require a wheelchair cushion that produces lower than average sub-ischial pressures.

In order to identify patients with low ischial relief performance a simple 
device has been developed and is currently undergoing trials in the pressure clinic at Philipshill Hospital. This device records the time devoted to exercise and the total time during which the chair is used in the patient's normal environment. The design of this fully portable device is described in full by Davies (1978) and consists of switches placed strategically in the patient's wheelchair cushion and connected via logic circuitry to digital watches (Fig. 2).

It is hoped that results from this device will enable routine assessment of patient exercise duration to be made in the future.

\section{Measurement of Sitting Posture}

A poor sitting posture often produces very high ischial pressures. Poor sitting posture is not difficult to detect either by observation or inference from ischial pressure measurements. Regular measurement of spinal curvature in the pressure clinic is useful for some patients, especially if treatment by remedial physiotherapy is advocated.

A simple device has been constructed for the Philipshill pressure clinic consisting of metal probes passing through an array of holes in a vertical peg-board frame. The ends of the probes are located against specific spinous processes after passing through an open-weave canvas replacement for the wheelchair backrest. Measurements are made when the patient is assuming his habitual sitting posture (Fig. 3).

Skilful modification of the wheelchair cushion by experienced personnel will often remedy an inadequate pressure distribution caused by a poor posture. In the authors' experience one of the most common causes of poor sitting posture is a torn wheelchair back.

\section{Application of Thermal Imaging}

Hahn and Black (1977) have investigated the use of thermal imaging techniques in the pressure clinic, enabling assessment of the patient/support match

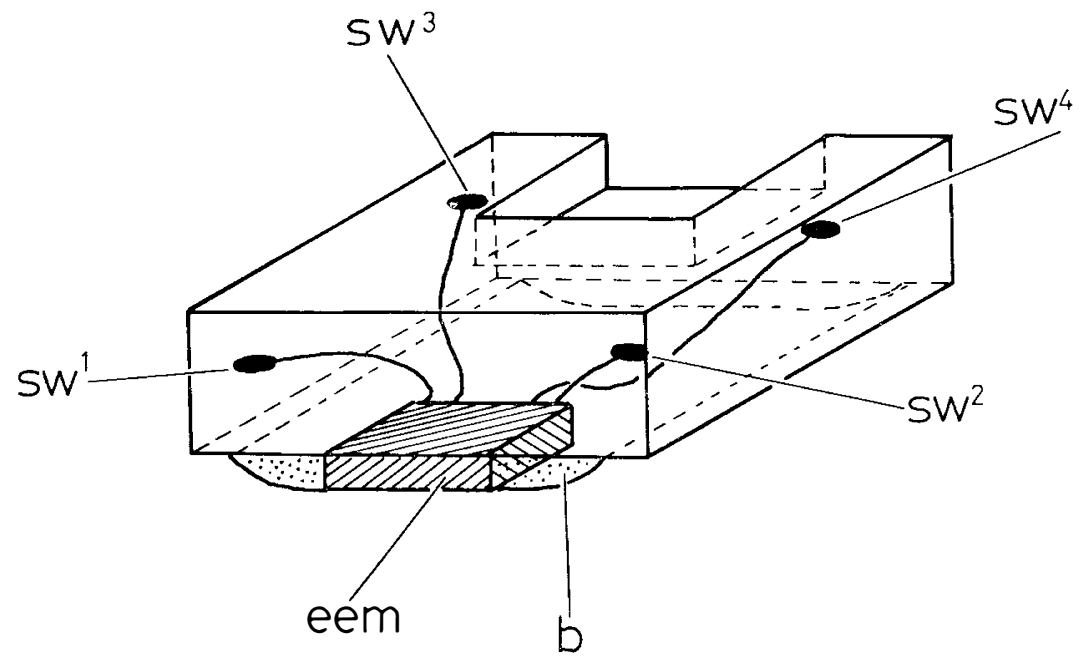

FIG. 2

Diagram illustrating location of the electronic exercise monitor (eem) in the 'Plastazote' base (b) of a wheelchair cushion. The four switches (sw) are embedded within the cushion below the areas loaded by the thighs $\left(\mathrm{sw} /{ }^{1} \mathrm{sw}^{2}\right)$ and trochanters $\left(\mathrm{sw}^{3}, \mathrm{sw}^{4}\right)$. 


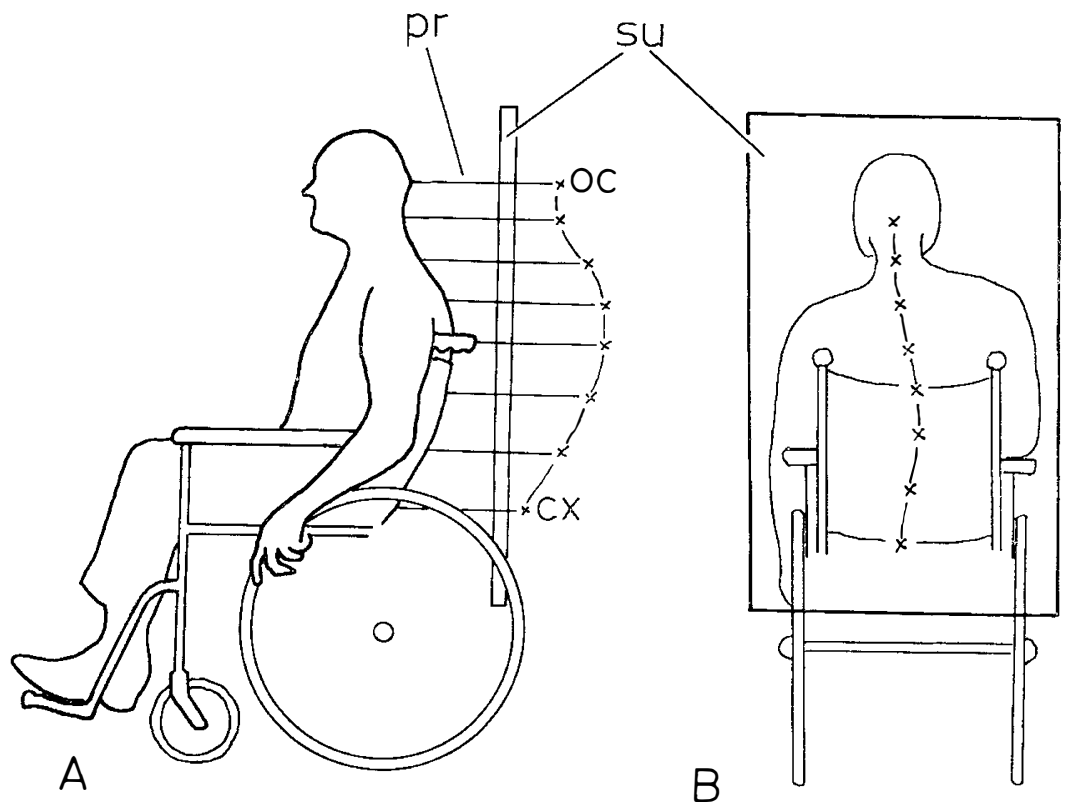

FIG. 3

Diagrammatic lateral (A) and rear (B) views illustrating the method employed to record spinal curvature. Probes of uniform length (pr) are pushed through a vertical peg-board support (su) and an open weave canvas wheelchair back to impinge upon the lower occipital prominence (oc), coccyx (cx), and a selection of intermediate sites which best demonstrate the curvature.

by measuring the thermal response of the skin following use of the support. Areas of skin enduring prolonged ischaemia often show regions of persistent erythema accompanied by local elevation of skin temperature. However other body/support interface parameters (e.g. high humidity, poor thermal dissipation, shear forces) may be responsible for producing similar thermal responses to stress.

Less expensive techniques are being investigated at the Philipshill pressure clinic employing radiometry and simple thermocouple systems.

\section{Results from Analysis of Patient Data}

Patient records at the Rancho Los Amigos pressure clinic have yielded data that are of particular interest because a large number of spinal injury patients were observed and treated using the same methods by the same staff over a short period of time. The data have enabled a comparison to be made between the pressure produced at the body/support interface and the presence of persistent skin redness or pressure sores.

Figure 4 presents the relationship between the pressure and skin conditions of a group of 657 spinal injury outpatients. Correlation by linear regression analysis indicates a correlation coefficient of 0.949 with a significance of 0.1 per cent ( 57 cases) for the relationship between pressure and the presence of ischial pressure sores. A similar analysis indicates a correlation coefficient of 0.903 with a significance of 1.5 per cent (IOO cases) for the relationship between pressure and 

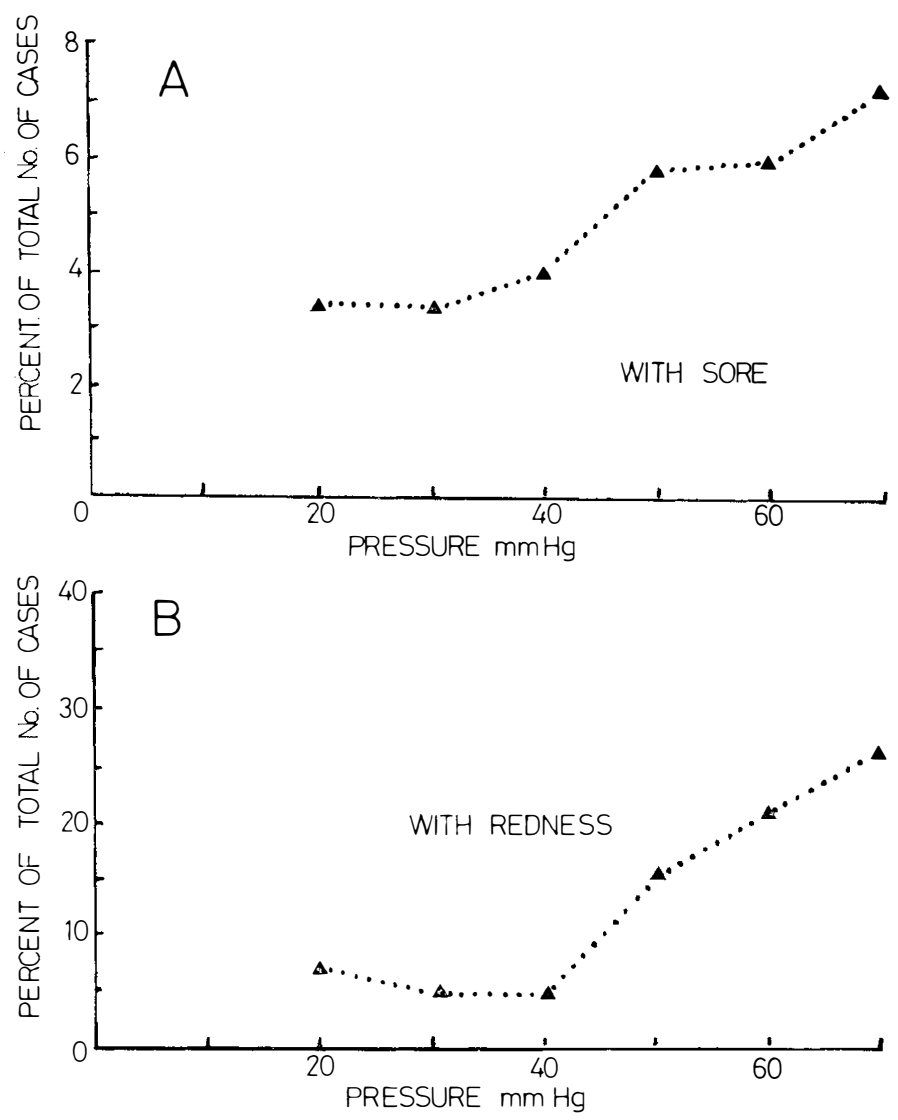

FIG. 4

Graphical representation of the incidence of (A) pressure sores, (B) skin redness over the ischial tuberosities as a percentage of all patients observed versus the pressure beneath the ischial tuberosities. The total number of patients observed $=657$.

skin redness. The choice of $30 \mathrm{mmHg}\left(4^{\circ} \circ \mathrm{kPa}\right)$ by Rogers (1973) as a maximum permissible pressure beneath the ischial tuberosities appears to be well founded.

The direct correspondence between the presence of ischial pressure sores and high pressures beneath the ischial tuberosities while using the wheelchair is evidence to support the principles of weight redistribution upon which pressure clinics are based. Further examination of patient records enables the techniques employed in the pressure clinic for weight redistribution to be matched against some commercial wheelchair cushions.

Table I represents in tabular form the incidence of ischial pressure sores and skin redness according to the type of support used by patients attending the pressure clinic. The patients listed as using pressure clinic-fitted cushions had been doing so for a minimum of 3 months, the observations being made prior to refitting. The measurements and skin observations for the patients using the other supports listed were made at their first visit to the pressure clinic prior to the fitting procedure.

Caution should be exercised when comparing the results for different cushions against each other, since in some cases the number of patients involved is very 


\section{TABLE I}

Skin condition of spinal injury patients attending pressure clinic according to type of cushion used. Numerals in parentheses are percentage of total

\begin{tabular}{|c|c|c|c|c|}
\hline $\begin{array}{l}\text { Cushion } \\
\text { type }\end{array}$ & $\begin{array}{l}\text { Ischial } \\
\text { sores }\end{array}$ & $\begin{array}{l}\text { Ischial } \\
\text { redness }\end{array}$ & Healthy & Total \\
\hline Latex F. & I6 (I2.2) & $27(20 \cdot 6)$ & $88(67 \cdot 2)$ & I3I \\
\hline Lo. Den. F. & $3(10 \cdot 7)$ & $7(25 \cdot 0)$ & I $8(64 \cdot 3)$ & 28 \\
\hline Air & $4(\mathrm{I} 8 \cdot 2)$ & $5(22 \cdot 7)$ & I3 $\left(59^{\circ} \mathrm{I}\right)$ & 22 \\
\hline Water/F. & $2(22 \cdot 2)$ & $\mathrm{I}(\mathrm{I} I \cdot \mathrm{I})$ & $6(66 \cdot 7)$ & 9 \\
\hline Gel & $8(33 \cdot 3)$ & $3(12.5)$ & I3 $\left(54^{\cdot 2}\right)$ & 24 \\
\hline 'Adaptaire' & IO $(7 \cdot 6)$ & I $8(13.7)$ & $103(78 \cdot 6)$ & I3I \\
\hline Pressure clinic & I $2(5 \cdot 4)$ & $31(140)$ & I $78(80 \cdot 5)$ & 221 \\
\hline Total & $55(9 \cdot 7)$ & $92(\mathrm{I} 6 \cdot 2)$ & $419(74 \cdot 0)$ & 566 \\
\hline
\end{tabular}

Skin condition data was missing for 43 cases.

small and may lead to substantial errors in interpretation. A statistical comparison employing the chi-squared test between the number of patients with ischial pressure sores using the pressure clinic-fitted cushion and the number of patients with ischial sores using the other cushions confirms that significantly fewer sores were developed on the pressure clinic-fitted cushions (at the $<0 \cdot 1$ per cent level). A similar test comparing the incidence of skin redness on the pressure clinic-fitted cushion with the other cushions was inconclusive.

A comparison is made in Table II between the number of patients with subischial pressures greater or less than $40 \mathrm{mmHg}(5.3 \mathrm{kPa})$ according to the type of cushion used. Again caution is recommended when making comparisons involving categories with only a small number of patients. The chi-squared test confirms that a greater proportion of the patients using the pressure clinic-fitted cushion have pressures lower than $40 \mathrm{mmHg}$ when compared with patients using the other cushions (at the $<0 \cdot$ I per cent level).

If the number of patients in each cushion category with sub-ischial pressures greater than $40 \mathrm{mmHg}$ is expressed as a percentage of the total number of patients using that cushion and then plotted against the percentage of the patients with

\section{TABLE II}

Sub-ischial pressure of spinal injury patients attending pressure clinic according to type of cushion used. Numerals in parentheses are percentage of total

\begin{tabular}{lcrr}
\hline Cushion type & $\begin{array}{c}\text { Ischial pressure } \\
<40 \mathrm{mmHg}\end{array}$ & $\begin{array}{c}\text { Ischial pressure } \\
>40 \mathrm{mmHg}\end{array}$ & Total \\
\hline Latex F. & $23(\mathrm{I} 6 \cdot 4)$ & II $7(83 \cdot 6)$ & I 40 \\
Lo. Den. F. & $6(\mathrm{I} 9 \cdot 3)$ & $25(80 \cdot 6)$ & $3 \mathrm{I}$ \\
Air & $3(\mathrm{I} 4 \cdot 3)$ & $\mathrm{I} 8(85 \cdot 7)$ & $2 \mathrm{I}$ \\
Water/F. & $5(50 \cdot 0)$ & $5(50 \cdot 0)$ & I0 \\
Gel & I $(4 \cdot 3)$ & $22(95 \cdot 6)$ & 23 \\
'Adaptaire' & $50(34 \cdot 2)$ & $96(65 \cdot 8)$ & I 46 \\
Pressure clinic & IOO (42.0) & I38 (58.0) & 238 \\
$\quad$ Total & I $88(30 \cdot 9)$ & $42 \mathrm{I}(69 \cdot \mathrm{I})$ & 609 \\
\hline
\end{tabular}


either healthy, redness or pressures sores on the skin over the ischial tuberosities, then the relationship shown in Figure 5 is obtained. This result implies that the control of sub-ischial pressure can be a primary aid in reducing the incidence of pressures in spinal injury patients using commercial or custom-built wheelchair cushions.

\section{Conclusion}

The results of this study indicate that the incidence of pressure sores affecting the skin covering the ischial tuberosities of spinal injury patients may be significantly reduced if adequate redistribution of body weight is achieved employing modified foam blocks. The pressure clinic is an excellent environment in which to employ the principles of weight redistribution, having facilities for interface pressure measurement and maintenance of patient records.

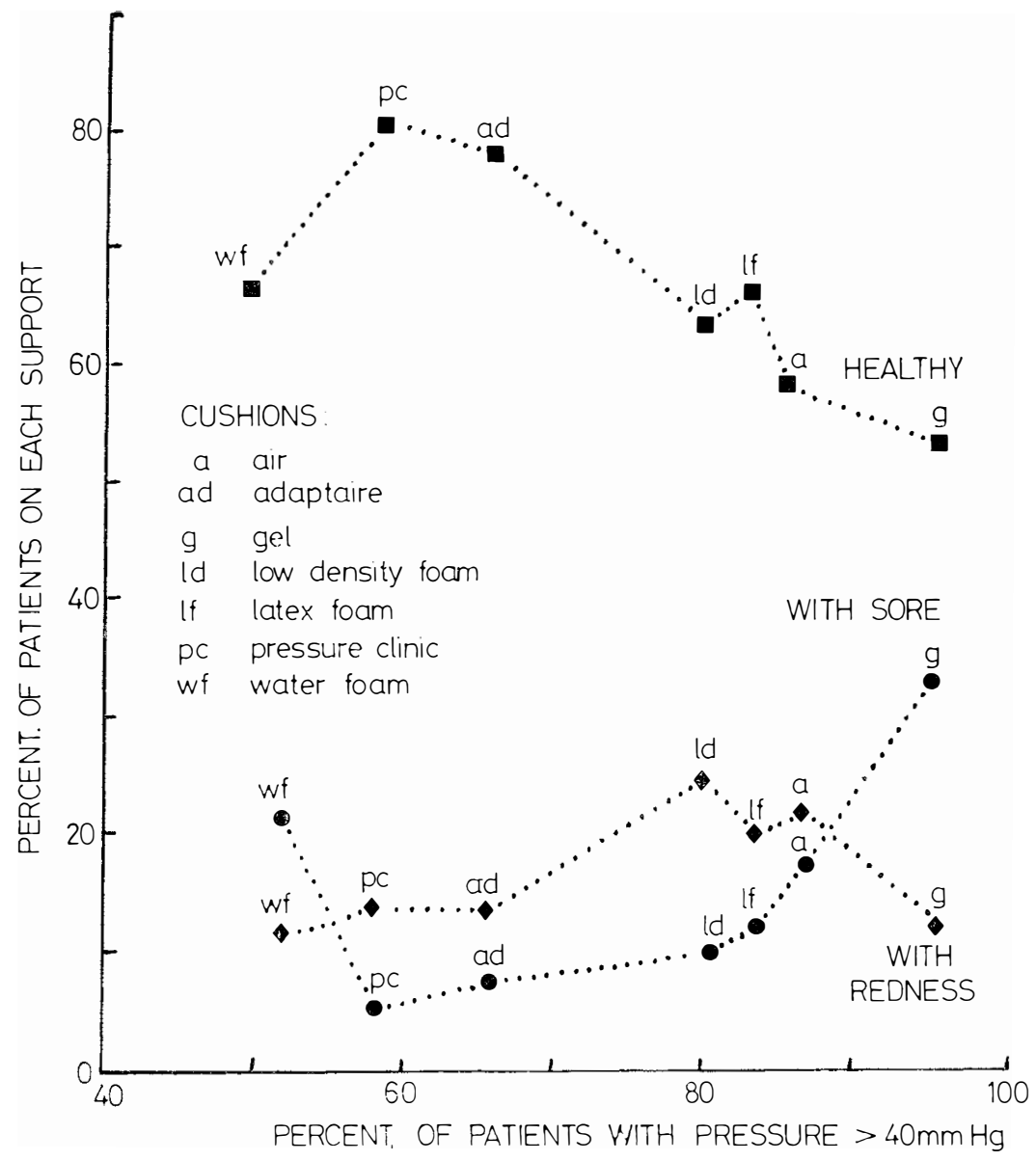

FIG. 5

Graphical representation of grouped patient data according to wheelchair cushion type. Cushions with a high proportion of patients with sub-ischial pressures above $40 \mathrm{mmHg}$ $(5.3 \mathrm{kPa})$ show a higher incidence of pressure sores or a smaller percentage of patients with healthy skin over the ischial tuberosities. Only nine patients used the water/foam cushions, which may account for the apparently anomalous results obtained with this support. 
Despite these methods some patients continue to develop pressure sores. Some may be attributable to falls or damage during, for example, transfer from car to chair. Others, however, can be attributed to inadequate support while sitting. In some cases the patient's armchair or car seat may be implicated. Although the techniques and concepts of the pressure clinic may be readily applied to domestic supports, the logistics of treating large numbers of patients in their homes have yet to be established.

The authors anticipate that the identification of patients with low exercise frequencies or asymmetric postures using simple devices will enable appropriate compensatory techniques to be adopted.

\section{SUMMARY}

The concept of a wheelchair cushion-fitting clinic for the prevention of pressure sores is reviewed and some recent refinements described. The results from analyses of patient data are presented which confirm that pressure measurements at the cushion/ischial tuberosity interface provide a direct indication of the adequacy and safety of the cushion in use.

\section{RÉSUMÉ}

Le concept d'une 'clinique coussion' mesure d'une chaise pour la prevention de l'escarres pressions est revue et quelques recent approuvements sont decus. Les resultats d'une analysis de les informations des patients sont presentes ce qui confirment que le measurement de la pression a la coussion/ischial tuberosite interface donne une directe indication du suffisance du coussion de'emploi.

\section{ZUSAMMENFASSUNG}

Eine Methode für Druckmessung der Unterflüche der Tuberositae ischiae ist diskutiert und die Techniques von Messung die Haufigkeit der einer Patienten habituellen Übung und Körperhaltung im Sitzen werden beschrieben. Die resultierenden Ergebnisse erzielt an 600 traumatisch Spinal Cord Patienten des Rancho Los Amigos werden berichtet und die Bedeutung eines leichten Druckes unterhalb der ischialen Tuberositae wird betont als Indikator für Rollstuhlkissen.

Acknowledgements. The work presented is based on valuable collaboration with the Rehabilitation Engineering Group at Rancho Los Amigos Hospital, Downey, Ca., U.S.A. (Director, Dr J. B. Reswick) and Mr J. Rogers (Rogers Associates, Los Angeles, U.S.A.). The authors also wish to thank professors R. M. Kenedi and J. P. Paul (Bioengineering Unit, Strathclyde University) and Mr A. McDougall and Dr I. C. Seymour (Philipshill Hospital, Glasgow). The work at Philipshill Hospital is sponsored by the Scottish Home and Health Department.

\section{REFERENCES}

Barbenel, J. C., Jordan, M. M., Nicol, S. M. \& Clark, M. O. (1977). Incidence of pressure sores in the Greater Glasgow Health Board Area. Lancet, 10, 548-550.

Cox, L. A. (1974). An Interim Report on the Nursing Project into the Management of Spinal Paralysis. Royal Perth Hospital, Australia. (Internal report.)

Davies, R. V. (1978). The Long Term Monitoring of Wheelchair Patient Activity with Special Reference to the Pressure Sore Problem. M.Sc. Thesis, University of Strathclyde, Glasgow.

Ferguson-Pell, M. W. (I977). Critical Assessment of the Effects of Pressure with Special Reference to the Development of Pressure Sores. Ph.D. Thesis, University of Strathclyde, Glasgow. 
Ferguson-Pell, M. W. \& WILKIE, I. C. (I978). Discussion contribution to Strathclyde Bioengineering Seminars, 'Rehabilitation of the Disabled'. Ed. R. M. Kenedi. Macmillan. (In preparation.)

Hahn, G. \& Black, R. C. (1977). Ontario Crippled Children's Hospital Center, tissue trauma program. Paraplegia, 15, 86-89.

Kosiak, M. (I959). Etiology and Pathology of Ischaemic ulcers. Arch. Phys. Med. Rehab., 40, 62-69.

MaNley, M. T., Wakefield, E. \& Key, A. G. (1977). The prevention and treatment of pressure sores in the sitting paraplegic. S. Afr. Med. F., 52, 77I-774.

Nelham, R. L. (1975). The manufacture of moulded supportive seating for the handicapped. Biomed. Eng., October, 379-38I.

Reswick, J. B. \& Rogers, J. E. (I976). Experience at Rancho Los Amigos Hospital with devices and techniques to prevent pressure sores. In Bed Sore Biomechanics. Ed. R. M. Kenedi, J. M. Cowden and J. T. Scales, pp. 30I-3IO. Macmillan, London.

Rogers, J. E.(I 1973). Tissue trauma group. In Annual Report of Progress. Rehabilitation Center at Rancho Los Amigos Hospital (December 1972-November 1973). 